\title{
Concomitant taurine exposure counteracts ethanol-induced changes in locomotor and anxiety-like responses in zebrafish
}

\author{
Barbara D. Fontana ${ }^{1}$ (D) Tamie Duarte $^{2,3}$ - Talise E. Müller ${ }^{2,3}$ - Julia Canzian ${ }^{2,3}$ - Paola R. Ziani ${ }^{2}$. \\ Nathana J. Mezzomo ${ }^{2,4}$ - Matthew O. Parker ${ }^{1,5}$ • Denis B. Rosemberg ${ }^{2,3,5}$
}

Received: 14 June 2019 / Accepted: 18 November 2019/Published online: 30 November 2019

(C) The Author(s) 2019

\begin{abstract}
Taurine (TAU) is a $\beta$-amino sulfonic acid with pleiotropic roles in the brain, including the neuromodulatory activity via GABAergic and glycinergic agonism. This molecule is found at high concentrations in energy drinks and is often mixed with alcohol in beverages. Although TAU has a neuroprotective role in the brain, the putative risks of mixing TAU and EtOH are not fully understood. Here, we investigated whether TAU modulates locomotor and anxiety-like behavior in adult zebrafish by using the novel tank and light-dark tests following acute EtOH exposure at anxiogenic and anxiolytic concentrations. Zebrafish were individually exposed to water (control), TAU (42, 150, and $400 \mathrm{mg} / \mathrm{L})$, and EtOH (0.25\% $(\mathrm{v} / \mathrm{v})$ and $1 \%(\mathrm{v} / \mathrm{v}))$ both independently and cotreated for $1 \mathrm{~h}$. EtOH $0.25 \%$ and TAU produced U-shape anxiolytic-like behavior in the light-dark test, TAU 42 and 400 positively modulated EtOH effects, and TAU 150 exerted a protective effect. All TAU concentrations counteracted EtOH 1\%-induced locomotion impairment, as well as the anxiogenic-like behavior. Finally, all TAU concentrations when given independently or cotreated with EtOH $0.25 \%$ and $1 \%$ decreased the risk assessment of the lit compartment. Principal component analyses revealed that exploration and anxiety-like responses were the main behaviors that contribute to the effects of TAU and EtOH. Overall, we demonstrate that TAU differently modulates EtOH-induced anxiolytic- and anxiogenic-like behaviors depending on the concentration, suggesting a complex mechanism underlying TAU and EtOH interactions.
\end{abstract}

Keywords Alcohol $\cdot$ Energy drink $\cdot$ Anxiety $\cdot$ Exploration $\cdot$ Zebrafish

Barbara D. Fontana

barbara.fontana@port.ac.uk

$\triangle$ Denis B. Rosemberg

dbrosemberg@gmail.com

1 Brain and Behaviour Laboratory, School of Pharmacy and Biomedical Sciences, University of Portsmouth, England, UK

2 Laboratory of Experimental Neuropsychobiology, Department of Biochemistry and Molecular Biology, Natural and Exact Sciences Center, Federal University of Santa Maria, 1000 Roraima Avenue, Santa Maria, RS 97105-900, Brazil

3 Graduate Program in Biological Sciences: Toxicological Biochemistry, Federal University of Santa Maria, 1000 Roraima Avenue, Santa Maria, RS 97105-900, Brazil

4 Graduate Program in Pharmacology, Federal University of Santa Maria, 1000 Roraima Avenue, Santa Maria, RS 97105-900, Brazil

5 The International Zebrafish Neuroscience Research Consortium (ZNRC), 309 Palmer Court, Slidell, LA 70458, USA

\section{Introduction}

Ethanol (EtOH) is one of the most widely consumed psychoactive drugs worldwide (Degenhardt et al. 2008). EtOH acutely promotes a biphasic effect, where low to moderate doses are stimulant and higher doses induce depressant effects (Addicott et al. 2007). In the brain, the mechanisms underlying the effects of EtOH include neuroinflammation, glial effects, and impaired neuromodulation (Lasek 2016; Montesinos et al. 2016). Furthermore, alcohol has stressreducing properties, and the chronic use can escalate into alcohol use disorders (Cooper et al. 1995; Schroder and Perrine 2007), which frequently comorbid with anxietyrelated disorders (Grant et al. 2004; Kushner et al. 1990). Patients with mood and anxiety disorders use substances to cope with the negative symptoms associated with the diseases, thereby corroborating a high correlation between anxiety and alcohol use disorder. Then, increased alcohol 
consumption for a long period can facilitate substance use disorder (Turner et al. 2018).

Taurine (TAU) is a $\beta$-amino sulfonic acid found at high concentrations in energy drinks (Heckman et al., 2010) and is commonly mixed with alcohol in several popular beverages (Ferreira et al. 2004a; Ferreira et al. 2004b; Marczinski and Fillmore 2014). This molecule acts as osmotic regulator (Schaffer et al. 2010), membrane stabilizer (Lambert et al. 2015), antioxidant (Lerdweeraphon et al. 2013), and inhibitory neuromodulator (Wu and Prentice 2010), as well as in the maintenance of intracellular calcium metabolism (Foos and $\mathrm{Wu}$ 2002). Although most studies do not investigate the direct interaction of TAU/EtOH, the combined used of EtOH and energy drinks is associated to major health problems. Thus, the combined use of alcohol and energy drinks increases the number and time of drinks consumed, dehydration, and more severe and prolonged hangovers, leading to an increase number of alcohol poisoning reports (Patrick et al. 2014; Snipes and Benotsch 2013).

TAU modulatory activity has been shown to regulate distinct behaviors, causing a negative impact when associated with drugs of abuse depending on the concentration (Fontana et al. 2016; Fontana et al. 2018; Mezzomo et al. 2018). For example, high concentrations of TAU associated to alcohol can increase aggressive behavior (Fontana et al. 2016) and decrease seeking for conspecifics (Fontana et al. 2018) in zebrafish. The hypothesis underlying the negative interaction of TAU with alcohol suggests an involvement of $\mathrm{GABA}_{\mathrm{A}}$, where both molecules have an agonist role (Huxtable 1992; Olsen and Liang 2017; Wallner and Olsen 2008). Because the GABAergic system is involved in anxiety-related disorders (Lydiard 2003; Tasan et al. 2011) and considering that EtOH and TAU are concomitantly found in alcohol beverages, the study of their association is relevant to better understand how the interaction between these molecule can affect anxiety-related phenotypes in vertebrate systems.

The zebrafish (Danio rerio) is a suitable model species for modeling human diseases due to its high genetic and physiological homology, as well its well-characterized behavioral repertoire (Fontana et al. 2018; Kalueff et al. 2013; Parker et al. 2012; Stewart et al. 2015). Although EtOH and TAU alone modulate locomotion and anxietylike behaviors in zebrafish (Gerlai et al. 2000; Mezzomo et al. 2016), the influence of their cotreatment in anxietylike phenotypes has been poorly explored. Thus, we aimed to evaluate the role of TAU and EtOH (low and high concentrations) in modulating anxiety-like responses in zebrafish using two behavioral tests (novel tank and light-dark tests). Using the principal component analysis (PCA), we also assessed which parameters have more impact in the behavioral changes induced by TAU and EtOH concomitant exposure.

\section{Materials and methods}

\section{Animals}

Adult zebrafish (Danio rerio) (50:50 male: female ratio; wildtype; short fin phenotype) were obtained from a commercial supplier (Hobby Aquários, RS, Brazil). Animals were maintained for 2 weeks in $50 \mathrm{~L}$ tanks filled with non-chlorinated water at a density of two animals per liter under controlled temperature $\left(26 \pm 2{ }^{\circ} \mathrm{C}\right), \mathrm{pH}(7.0-7.5)$, and photoperiod cycle (14:10 light-dark; lights on at 7:00 a.m.). Fish were fed twice daily with commercial flake food (Alcon Basic ${ }^{\circledR}$, Alcon, Brazil). All behavioral tests were performed during the same time each day (between 10:00 a.m. and 4:00 p.m.) immediately after TAU or/and EtOH exposure. Importantly, two independent batches were used for the experiments, and each animal was tested in a single apparatus (novel tank or light-dark test) to avoid stress caused by subsequent manipulations. The tank water was changed after each trial to remove potential cues that influence behavior. Both housing and experimental conditions were in accordance to the National Institute of Health Guide for Care and Use of Laboratory Animals. All protocols used in this study were previously approved by the Ethics Commission on Animal Use of the Federal University of Santa Maria (process number 026/2014).

\section{Treatments}

To assess the effects of TAU (Sigma, St. Louis, MO, USA) and EtOH (Merck, Darmstadt, Germany) association, fish were exposed individually in $500 \mathrm{~mL}$ beakers for $1 \mathrm{~h}$. The following groups were tested: control (non-chlorinated water), TAU alone at $42 \mathrm{mg} / \mathrm{L}$ (TAU 42), $150 \mathrm{mg} / \mathrm{L}$ (TAU 150), and $400 \mathrm{mg} / \mathrm{L}(\mathrm{TAU} 400)$ and EtOH $0.25 \%(\mathrm{v} / \mathrm{v})$ alone or cotreated with TAU (TAU 42/EtOH $0.25 \%$, TAU 150/EtOH $0.25 \%$, and TAU $400 / \mathrm{EtOH} 0.25 \%)$ and EtOH $1 \%(\mathrm{v} / \mathrm{v})$ alone or cotreated with TAU (TAU 42/EtOH 1\%, TAU 150/EtOH $1 \%$, and TAU 400/EtOH 1\%). TAU concentrations were based on previous reports, which showed anxiolytic-like properties, as well as a significant modulatory role on EtOHinduced behaviors (Fontana et al. 2016; Mezzomo et al. 2016; Rosemberg et al. 2012). In order to assess both anxiolytic- and depressant-like effects of alcohol in zebrafish, two concentrations $(0.25 \% \mathrm{v} / \mathrm{v}$ and $1 \% \mathrm{v} / \mathrm{v})$ were chosen as described elsewhere (Gerlai et al. 2000). A total of 288 fish were used for the experiments.

\section{Novel tank diving test}

The novel tank diving test is one of the most used apparatus to assess locomotor and anxiety-like phenotypes, showing a high sensitivity to anxiolytic and anxiogenic manipulations (Egan et al. 2009; Kalueff et al. 2013; Levin et al. 2007; Maximino 
et al. 2010b; Mezzomo et al. 2016; Wong et al. 2010). After the exposure period, animals $(n=10-12)$ were placed individually in the apparatus $(25 \mathrm{~cm}$ length $\times 15 \mathrm{~cm}$ height $\times 6 \mathrm{~cm}$ width). Behaviors were recorded using a webcam for $6 \mathrm{~min}$ based on previous studies, where animals gradually spend more time in the top portion of a tank over the first $6 \mathrm{~min}$ of the test (Blaser and Rosemberg 2012; Egan et al. 2009; Mezzomo et al. 2016; Rosemberg et al. 2012; Wong et al. 2010). Data were analyzed in an automated fashion using a video-tracking software (ANY-maze ${ }^{\mathrm{TM}}$, Stoelting CO, USA) at a rate of 30 frames/s. The tank was divided in three virtual areas (bottom, middle, and top) to provide a detailed evaluation of the vertical activity. The following endpoints were measured: total distance traveled, absolute turn angle, latency to enter the top area, time spent in top area, transitions to top area, and immobility.

\section{Light-dark test}

The light-dark test is a complementary task to assess anxiety-like responses, which explores the natural tendency of adult zebrafish to avoid brightly lit environments (Blaser and Rosemberg 2012; Maximino et al. 2010a; Maximino et al. 2010b; Rosemberg et al. 2011). This test was performed in experimental tanks $(30 \mathrm{~cm}$ length $\mathrm{x}$ $10 \mathrm{~cm}$ width $\times 15 \mathrm{~cm}$ height) divided into two equally sized partitions using black or white self-adhesive film to cover the walls and floor. After the treatments, zebrafish $(n=10$ 12) were gently placed in the white partition of the tank, and their behaviors were quantified for 6 min using the ANY-maze ${ }^{\mathrm{TM}}$ software (Stoelting CO, USA) at a rate of $30 \mathrm{frames} / \mathrm{s}$. The following endpoints were determined: time spent in lit area, transitions to lit area, latency to enter the dark area, and number of risk assessment episodes. Risk assessment was assessed manually by three trained observers blinded to the experimental condition (inter-rater reliability $>0.90)$ and defined as a fast $(>1 \mathrm{~s})$ entry in the white compartment followed by reentry in the black compartment, or as a partial entry in the lit area (Kalueff et al. 2013; Mezzomo et al. 2016).

\section{Statistics}

Data were checked for normality and homogeneity of variances via the Kolmogorov-Smirnov and Bartlett's tests, respectively. Data were expressed as means \pm standard error of the mean (S.E.M) and further analyzed by two-way or threeway ANOVA followed by Tukey's multiple comparisons test. Given the asymmetric data distribution of the latencies to enter to the top/dark areas, the respective parameters were expressed as median \pm interquartile range and analyzed by Kruskal-Wallis test followed by Dunn's multiple comparison test. PCA was performed to evaluate the potential correlation between variables of the novel tank diving task and the lightdark test, separately. The component matrix was subjected to Varimax rotation with Kaiser normalization. Components (or factors) with eigenvalue lower than 1 were disregarded, and measures with loadings greater than 0.4 were retained. The first principal component (PC1) explains the largest percentage of data variance. Data were analyzed in SPSS 19 (IBM SPSS Statistics, version 19). Post hoc analyses were performed using Tukey's multiple comparisons test when appropriate. The significance was set at $p \leq 0.05$.

\section{Results}

\section{TAU counteracts EtOH-induced locomotor deficits and anxiogenic-like behavior}

Figure 1 shows the effects of TAU and EtOH in the novel tank task. Two-way ANOVA yielded a significant EtOH effect on distance traveled $\left(F_{(2,116)}=18.51, p<0.0001\right)$, absolute turn angle $\left(F_{(2,116)}=67.65, p<0.0001\right)$, and transitions to top area $\left(F_{(2,116)}=33.04, p<0.0001\right)$. Furthermore, a significant TAU $\times$ EtOH interaction was observed for the time spent in top $\left(F_{(6,116)}=3.070, p=0.0081\right)$ and transitions to top area $\left(F_{(6,116)}=4.090, p=0.0009\right)$. TAU $42(p<0.005)$ and 150 $\mathrm{mg} / \mathrm{L}(p<0.005)$ alone increased the latency to enter the top area, while EtOH $0.25 \%$ alone did not show significant differences in the novel tank test when compared with control. Regarding the effects of EtOH 1\%, only EtOH $1 \%$ and TAU 150/EtOH $1 \%$ groups showed a reduced distance traveled. Additionally, EtOH $1 \%$ alone and all TAU-associated groups showed decreased absolute turn angle and transitions to top area, except TAU 400/EtOH 1\%, which revealed only a decreased absolute turn angle. Animals exposed to $1 \% \mathrm{EtOH}$ alone spent less time in top area, but this effect was abolished by all TAU concentrations. Temporal analyses of the time spent in the top area showed that EtOH significantly affected the diving responses across time $\left(F_{(10,116)}=4.634, p<\right.$ $0.0001)$. Finally, a significant interaction of time $\times$ TAU $\times$ EtOH was observed $\left(F_{(30,116)}=1.647, p=0.017\right)$ (data not shown).

\section{TAU induces biphasic reduction of anxiolytic-like behavior}

Figure 2 shows the behavioral responses of zebrafish in the light-dark test. Significant TAU effects were observed in the time spent in lit area $\left(F_{(3,122)}=2.404, p=0.0440\right)$ and risk assessment episodes $\left(F_{(3,122)}=11.43, p<0.0001\right)$. Significant EtOH effects were observed for the time spent in lit area $\left(F_{(2,122)}=12.99, p<0.0001\right)$, average duration of entry in the lit area $\left(F_{(2,122)}=4.233, p=0.0167\right)$, and risk assessment episodes $\left(F_{(2,122)}=48.57, p<0.0001\right)$. Furthermore, a TAU $\times$ 


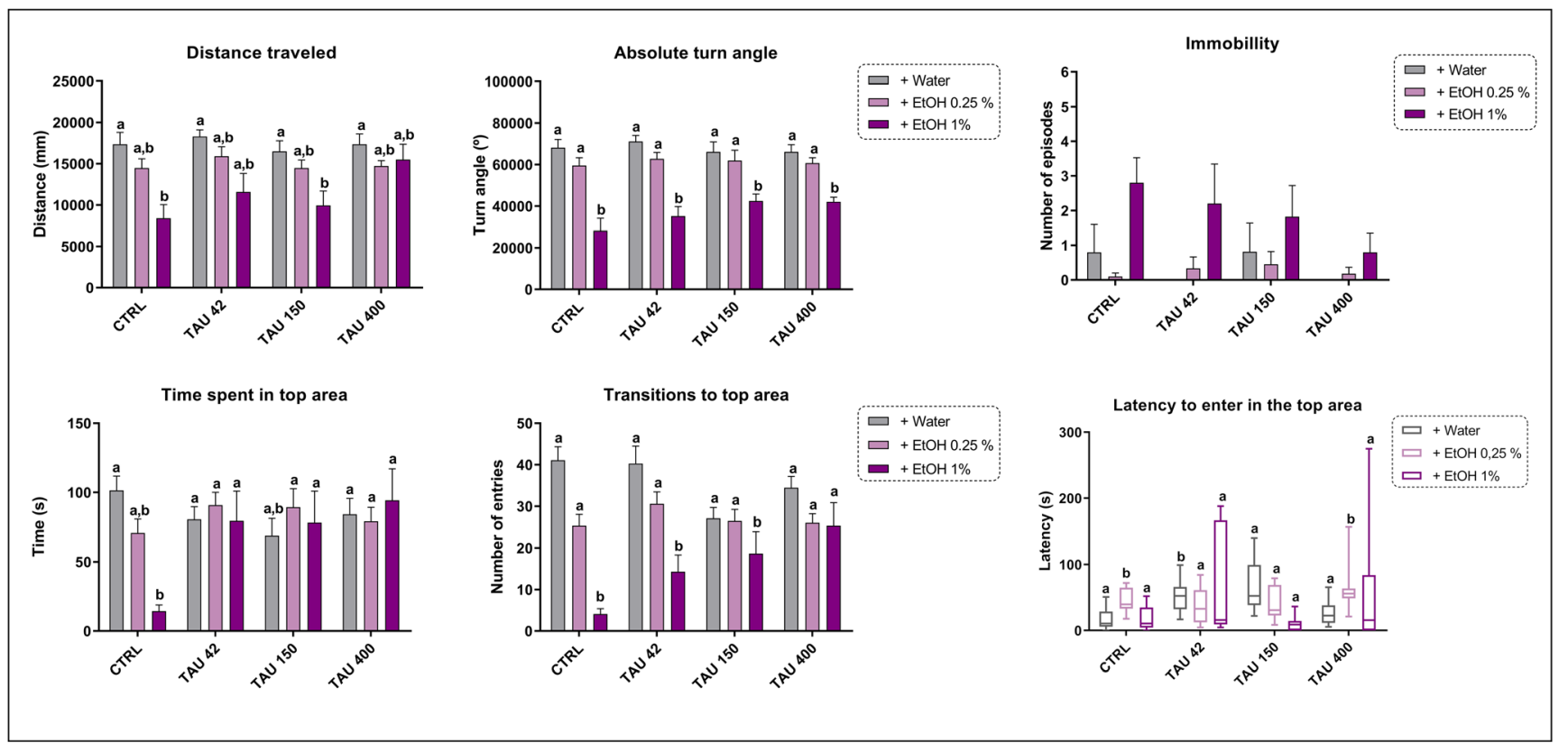

Fig. 1 Effects of TAU and/or EtOH in the novel tank task. Data were represented as mean \pm S.E.M. and analyzed by two-way ANOVA, followed by Tukey's multiple comparison test. Different letters indicate statistical differences between groups $(p<0.05, n=12$ per group)

EtOH interaction was observed for both time spent in lit area $\left(F_{(6,122)}=2.404, p=0.0313\right)$ and risk assessment episodes $\left(F_{(6,122)}=4.403, p=0.0004\right)$. The effects of TAU alone in the light-dark test revealed that TAU 42 and TAU 400 groups spent more time in the lit area. Regarding EtOH $0.25 \%$ effects, EtOH alone increased the time spent in lit area. Two-way ANOVA revealed that EtOH 1\%, TAU42/EtOH 1\%, and
TAU400/EtOH $1 \%$ groups spent more time in the lit area. Additionally, TAU groups (alone or concomitantly exposed to alcohol) showed decreased number of risk assessments. Temporal analyses yielded a significant time $\times \mathrm{TAU} \times \mathrm{EtOH}$ interaction $\left(F_{(30,122)}=2.431, p=0.000\right)$, while only EtOH modulated the light-dark responses across time $\left(F_{(10,122)}=\right.$ $1.968, p=0.034)$.

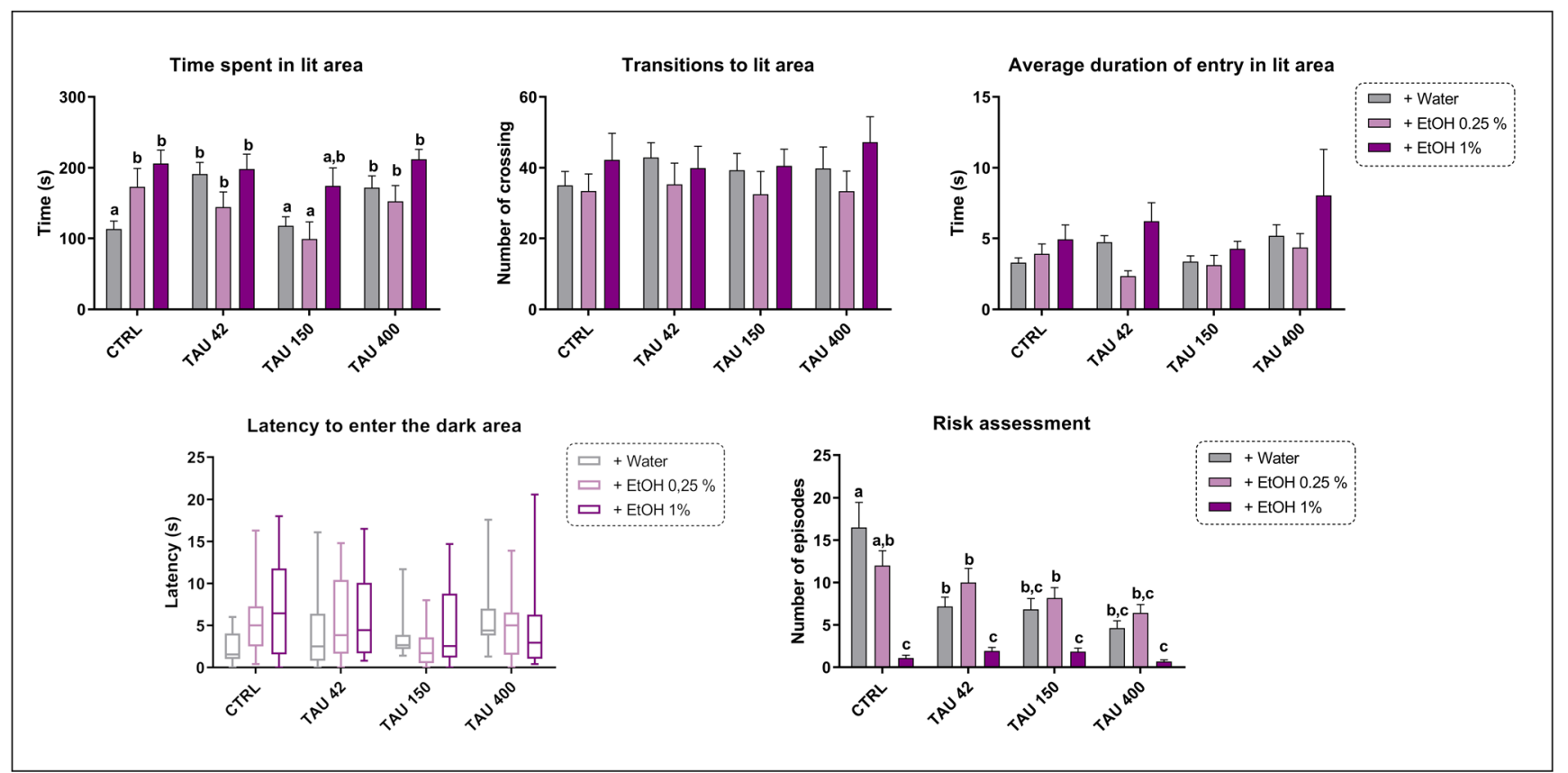

Fig. 2 Effects of TAU and/or EtOH in the light-dark test. Data were represented as mean \pm S.E.M. and analyzed by two-way ANOVA, followed by Tukey's multiple comparison test. Different letters indicate statistical differences between groups $(p<0.05, n=12$ per group) 


\section{Exploratory- and anxiety-related parameters are the main components involved in the behavioral responses measured}

Figure 3 and 4 show the main components driving the behavioral responses of zebrafish when exposed to TAU or/and EtOH in the novel tank and light-dark test, respectively. For novel tank and light-dark tests, the KaiserMeyer-Olkin measure of sampling adequacy were 0.700 and 0.512 , respectively. Bartlett's tests of sphericity were also significant for novel tank task $(\chi 2=244.236, \mathrm{df}=15$, $p<0.000)$ and light-dark test $(\chi 2=36.883, \mathrm{df}=10, p<$ $0.0001)$.

In the novel tank task, PCA extracted two principal components which accounted for more than $63 \%$ of the total variance (Fig. 3A). PC1 was associated with locomotion and exploratory activity, with positive component loadings for distance traveled, angular velocity, transitions to top, and a negative component loading for immobility. Meanwhile, the PC2 was associated with anxiety-related parameters, with a negative component for time spent in top and a positive component for latency to enter in top area. Two-way ANOVA yielded significant effects of TAU $\times \mathrm{EtOH}$ interaction
$\left(F_{(6,116)}=3.332, p=0.0044\right)$, TAU $\left(F_{(3,116)=3.582, p=}=\right.$ $0.0158)$, and $\operatorname{EtOH}\left(F_{(2,116)=33.20, p=0.0001)}\right)$ for the PC1. Post hoc analysis showed that EtOH $1 \%$ significantly affect the $\mathrm{PC} 1$, showing reduced values when concomitantly exposed with TAU $400 \mathrm{mg} / \mathrm{L}$. For the PC2, a significant TAU $\times$ EtOH interaction $\left(F_{(6,116)}=2.584, p=0.0215\right)$ was observed, in which TAU 150 vs TAU $150+$ EtOH $1 \%$ showed significant differences.

In the light-dark test, PCA extracted two principal components accounting for $60 \%$ of the total variance (Fig. 4A). PC1 was highly associated to anxiety-related parameters, in which the time spent in lit area was loaded as a positive component, while the average duration of entry in lit area and the risk assessment were loaded as negative components. PC2 was associated to exploratory patterns in the light-dark test, loading a positive component for transitions in lit area and a negative one for latency to enter the dark area. Significant TAU $\times$ EtOH interaction $\left(F_{(6,122)}=18.51, p=0.0001\right), \mathrm{TAU}\left(F_{(3,122)=}\right.$ $16.80, \mathrm{p}=0.0001)$, and $\mathrm{EtOH}\left(F_{(2,122)=} 63.26, \mathrm{p}=0.0001\right)$ effects were observed for the PC1 analysis. Post hoc analysis yielded a significant increase of PC1 values for TAU, EtOH $0.25 \%$, EtOH $1 \%$ alone, and TAU-associated groups when compared to the control (Fig. 4B).

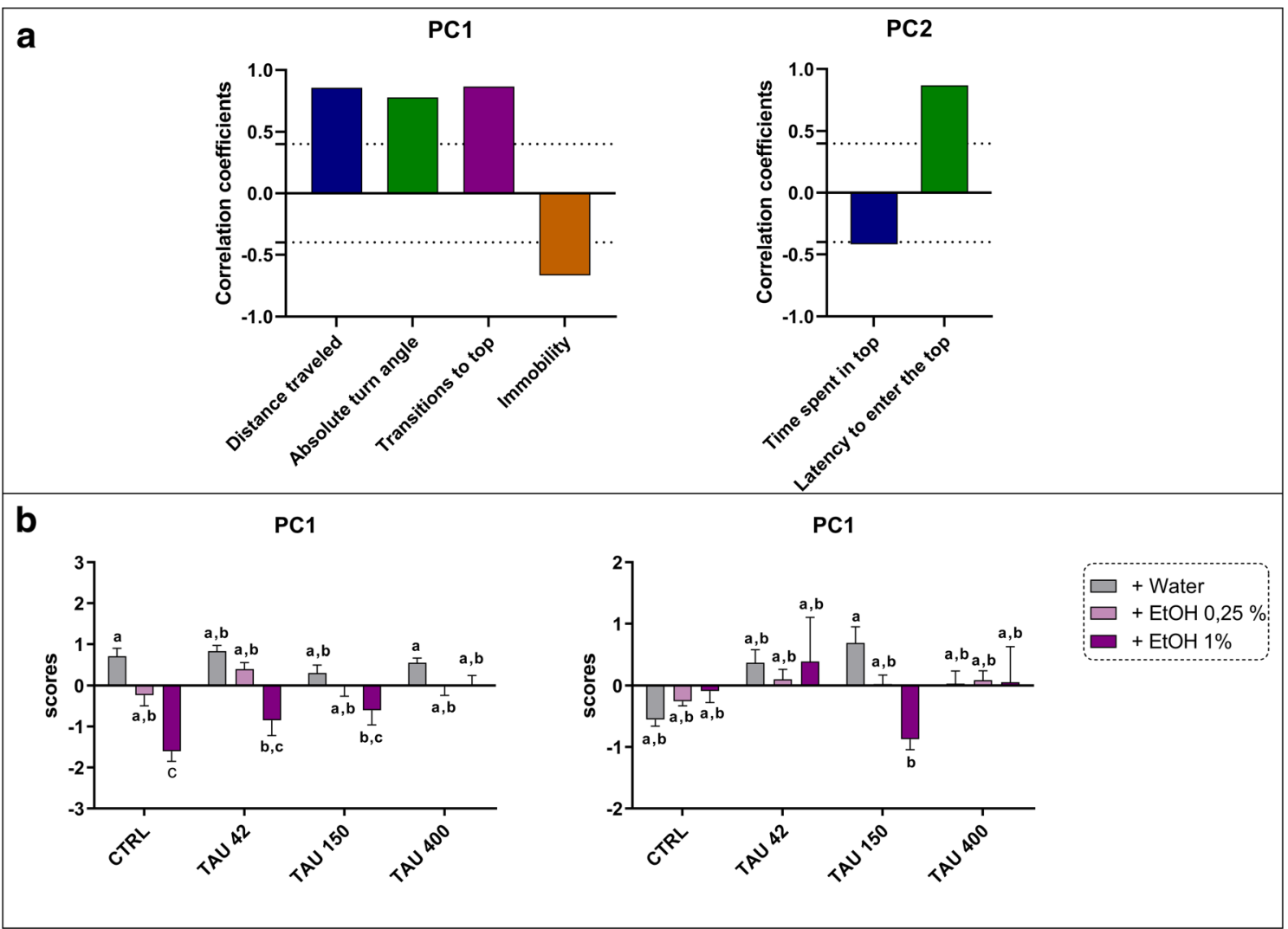

Fig. 3 Principal component analysis (PCA) for behavioral endpoints measured in the novel tank test. (A) Correlation coefficients between the behavioral endpoints for each PC. Dashed lines represent cut-off points, and only loadings greater than 0.3 or smaller than -0.4 are depicted. (B) Comparison of the values of two PC with eigenvalues greater than 1. Data are expressed as mean \pm SEM and analyzed by two-way ANOVA, followed by Tukey's post hoc test. Distinct letters indicate statistical differences between experimental groups $(p<0.05, n$ $=12$ per group) 


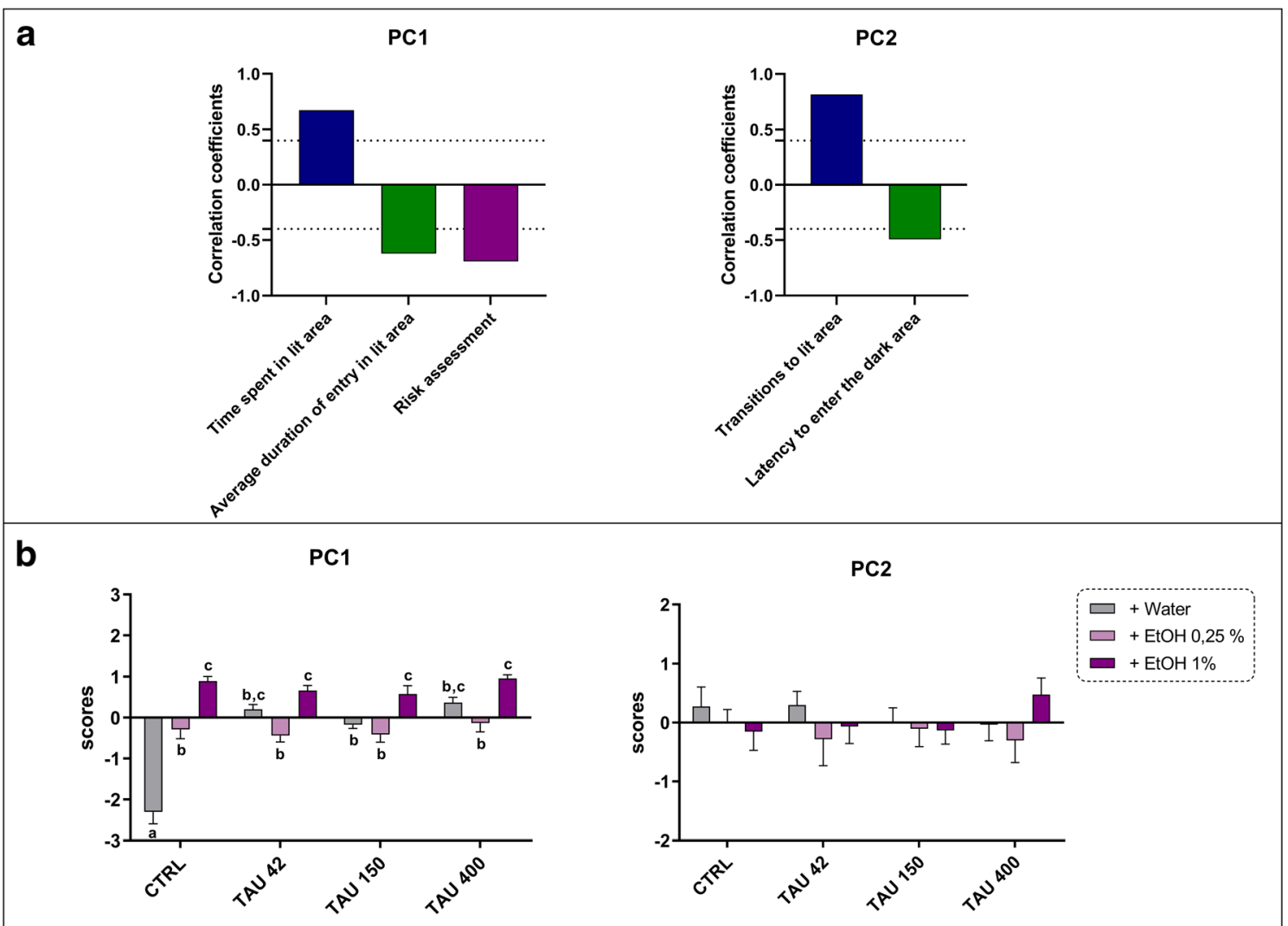

Fig. 4 Principal component analysis (PCA) for behavioral endpoints measured in the light-dark test. (A) Correlation coefficients between the behavioral endpoints for each PC. Dashed lines represent cut-off points and only loadings greater than 0.3 or smaller than -0.4 are depicted. (B)
Comparison of the values of two PC with eigenvalues greater than 1 . Data are expressed as mean \pm SEM and analyzed by two-way ANOVA, followed by Tukey's post hoc test. Distinct letters indicate statistical differences between experimental groups ( $p<0.05, n=12$ per group)

\section{Discussion}

In this study, we evaluated the concomitant effects of TAUand EtOH-induced changes in anxiety-like behaviors. We have shown for the first time that TAU attenuates EtOHinduced locomotor and anxiogenic-like phenotypes in the novel tank test. Moreover, when associated with EtOH, TAU results in a U-shaped response in light-dark test, exerting an anxiolytic-like effect in the lowest and highest concentrations, with a preventive effect at $150 \mathrm{mg} / \mathrm{L}$. Moreover, all TAU concentrations tested decreased the risk assessment to lit compartment.

$\mathrm{EtOH}$ is an anxiolytic molecule at lower concentrations. In humans, for example, alcohol may be consumed to counteract acute social anxiety, and this reinforcing effect can even increase future use with EtOH acting as a "social reward" (Goodman et al. 2018). The mechanisms underlying the biphasic effects of alcohol in anxiety-related behaviors include the antagonism of glutamatergic receptors and the increase in dopamine and serotonin (5-HT) levels (Alasmari et al. 2018; Deehan et al. 2016). Additionally, high EtOH concentrations positively modulate $\mathrm{GABA}_{\mathrm{A}}$ and $\mathrm{GABA}_{\mathrm{B}}$ receptors (Frye and Fincher 1996; Krystal et al. 2003; Olsen and Liang 2017). As observed previously (Gerlai et al. 2000), EtOH $0.25 \%$ showed anxiolytic-like effects in the light-dark test. Conversely, EtOH $1 \%$ altered exploration, showing anxiogenic-like responses in the novel tank test (Blaser and Penalosa 2011; Gebauer et al. 2011; Gerlai et al. 2000; Rosemberg et al. 2012; Tran and Gerlai 2013). However, the same EtOH concentration increased the time spent in lit area in the light-dark test. High alcohol concentrations can affect motor function and visual perception (Calhoun et al. 2004; Nutt and Peters 1994). In fact, EtOH $1 \%$ has been associated to changes in perception (Gerlai et al. 2000; Oliveira et al. 2013). Corroborating these findings, we observed that high EtOH concentrations significantly decreased the PC1 in the novel tank suggesting an impairment in their locomotor profile. Thus, the conflicting data observed in the light-dark test could be related to reduced swimming activity and/or even changes in visual perception when zebrafish are tested in a tank with two different contexts.

TAU alone displayed an anxiolytic profile at the 42 and 400 $\mathrm{mg} / \mathrm{L}$ without modulating EtOH-induced responses. TAU has anxiolytic-like effects when zebrafish behavior is assessed in the novel tank and in the light-dark tests (Mezzomo et al. 2016). Similar concentration-dependent responses were also previously described, where TAU potentiates EtOH-increased 
aggression at the lowest and highest concentration, while 150 $\mathrm{mg} / \mathrm{L}$ displays anti-aggressive action (Fontana et al. 2016). Although TAU changed anxiety-like profiles at the lowest and highest concentration, TAU $150 \mathrm{mg} / \mathrm{L}$ prevented anxiolytic-like effects of alcohol at $0.25 \%$ and decreased EtOH $1 \%$-induced changes in the light-dark test. All TAU concentrations alone and associated to EtOH also decreased the number of risk assessment episodes. The reduction of risk assessment episodes was previously observed in a fear-related task, where animals showed less caution when exploring the compartment close to a predator (Fontana et al. 2018). Moreover, the lowest and highest concentrations protected against EtOH 1\%-induced locomotor impairment. As observed here, mounting evidence shows that TAU does not change locomotion (Fontana et al. 2016; Fontana et al. 2018; Mezzomo et al. 2016; Rosemberg et al. 2012). In zebrafish, TAU pretreatment decreases alcohol content in the brain and prevents EtOH-induced locomotor changes, suggesting a direct influence of EtOH levels in the locomotion (Rosemberg et al. 2012). Additionally, TAU counteracts EtOH-induced anxiogenesis by normalizing the transitions and time spent in top area, only at the highest concentration. TAU is a molecule endogenously produced through cysteine oxidation having important physiological role in living organisms (De Luca et al. 2015; Huxtable 1992; Vitvitsky et al. 2011). Although more studies are needed to fully understand how EtOH and TAU interact, the mechanisms responsible for TAU effects on behavior are mainly associated to the GABAergic and glycinergic agonism (Dzirkale et al. 2011; Frosini et al. 2006), as well as to the antagonism of NMDA receptors (Chan et al. 2014). Thus, the biphasic effect of TAU association may involve complex interactions of molecules with a certain receptor and/or regulatory neurochemical pathways (Calabrese and Baldwin 2001; Fontana et al. 2016; Fontana et al. 2018; Rosemberg et al. 2012).

Interestingly, EtOH did change the responses across time for the time spent in the top area and in the lit area, suggesting that $\mathrm{EtOH}$ suppresses the natural decrease of anxiety across time. However, although TAU increased the time spent in the lit area, no significant effect of TAU across time was observed for both anxiety-related tasks (novel tank and light-dark test). Analyzing the interaction of the three factors (time, TAU, and EtOH), a significant effect was observed. Altogether, these data suggest that TAU when associated to EtOH has a positive interaction across time and may attenuate alcohol suppressing the natural zebrafish behavioral response.

PCA analysis of the light-dark supported that both TAU 42 and 400 groups are significantly affecting anxiety-related parameters (PC1). Alcohol anxiolytic-like responses were also mainly observed in the light-dark test through the analysis of the $\mathrm{PC} 1$. For the novel tank, the $\mathrm{PC} 1$ was related to locomotion and $\mathrm{PC} 2$ to anxiety-related parameters. EtOH $1 \%$ clearly induced locomotor deficits, and this could be an important factor underlying alcohol-induced changes in anxiety-like phenotypes. TAU 150 counteracted the anxiolytic-like effects of EtOH $0.25 \%$, and all TAU concentrations reduced locomotor and anxiogenic effects of EtOH 1\%. Overall, TAU alone and associated to EtOH $0.25 \%$ presented a U-shaped profile for anxiolytic-like behavior in the light-dark test, and all TAU concentrations prevented anxiogenic-like responses in the novel tank diving test. These data suggest that the behavioral responses measured here reflect a complex interaction between both molecules.

The association of TAU with EtOH suggests a complex interaction with different behavioral domains (e.g., aggression, anxiety, and locomotion). This association leads to a U-shaped response in scototaxis-, aggression-, and antipredatory-like responses (Fontana et al. 2016). Importantly, a dose-response is observed for other behavioral domains, such as locomotion, anxiety (novel tank), and social behavior (Fontana et al. 2018). To date, TAU $150 \mathrm{mg} / \mathrm{L}$ associated to EtOH has positive effects in the light-dark test and aggressiveness. All TAU concentrations also reduced EtOH-induced locomotor deficits, suggesting a protective role of TAU in this specific behavior. However, concomitant alcohol and $400 \mathrm{mg} /$ L TAU exposure potentiates aggression in the mirror-induced aggression test (Fontana et al. 2016) and decreases the preference for conspecifics (Fontana et al. 2018). Because alcohol disinhibits punished behavior (Fillmore et al. 2008; Johansson and Hansen 2000), concomitant exposure to TAU and EtOH may have more dangerous impact since TAU also decreased the time close to the predator (Fontana et al. 2018).

Although the mechanisms underlying the modulatory role of TAU on EtOH-induced behaviors in zebrafish are still unclear, the complex behavioral effects observed in the presence of both molecules reinforce the involvement of different neurotransmitter systems. Further studies are needed to investigate how TAU and EtOH interact each other. Importantly, the dissociable patterns of behavior observed for the light-dark vs novel tank tests were previously reported (Maximino et al. 2010b; Blaser and Rosemberg 2012), suggesting that both tests are complementary rather than interchangeable and involve different motivational aspects.

\section{Conclusions}

In summary, our novel findings demonstrate that TAU shows a biphasic profile when co-exposed with $\mathrm{EtOH}$, where low and high TAU concentrations decrease anxiety and do not prevent alcohol-mediated anxiolysis. Meanwhile, the intermediate TAU concentration did not change anxiety-related parameters and has a protective effect against EtOH 0.25\%-induced behavioral changes. Moreover, all TAU concentrations prevented against sedative effects of alcohol by decreasing anxiogenic-like behavior and reducing locomotor deficits. 
Overall, TAU and EtOH concomitant exposure have complex behavioral outcomes against alcohol-induced anxiolytic and anxiogenic-like phenotypes, and care should be taken with their simultaneous use. Furthermore, more studies are necessary to investigate the mechanisms underlining how TAU exposure differently modulates EtOH-induced anxiolytic and anxiogenic phenotypes.

Funding information This study was financed in part by Coordenação de Aperfeiçoamento de Pessoal de Nível Superior (CAPES) - Finance code 001, Conselho Nacional de Desenvolvimento Científico e Tecnológico $(\mathrm{CNPq})$, and Fundação de Amparo à Pesquisa do Estado do Rio Grande do Sul (FAPERGS). D.B.R receives the CNPq research productivity grant (process number 305051/2018-0). His works is also supported by PROEX/CAPES (process number 23038.004173/2019-93; grant number 0493/2019) and by the PRONEM/FAPERGS (process number 16/25510000248-7) fellowship grants. MOP receives funding from the British Academy (UK) and the Foundation for Liver Research (UK). The funders had no role in study design, data collection and analysis, decision to publish, or preparation of the manuscript.

\section{Compliance with ethical standards}

Conflict of interest The authors declare that they have no conflict of interest.

Open Access This article is distributed under the terms of the Creative Commons Attribution 4.0 International License (http:// creativecommons.org/licenses/by/4.0/), which permits unrestricted use, distribution, and reproduction in any medium, provided you give appropriate credit to the original author(s) and the source, provide a link to the Creative Commons license, and indicate if changes were made.

\section{References}

Addicott MA, Marsh-Richard DM, Mathias CW, Dougherty DM (2007) The biphasic effects of alcohol: comparisons of subjective and objective measures of stimulation, sedation, and physical activity. Alcohol Clin Exp Res 31:1883-1890

Alasmari F, Goodwani S, McCullumsmith RE, Sari Y (2018) Role of glutamatergic system and mesocorticolimbic circuits in alcohol dependence. Prog Neurobiol 171:32-49

Blaser RE, Penalosa YM (2011) Stimuli affecting zebrafish (Danio rerio) behavior in the light/dark preference test. Physiol Behav 104:831837

Blaser RE, Rosemberg DB (2012) Measures of anxiety in zebrafish (Danio rerio): dissociation of black/white preference and novel tank test. PloS one 7:e36931

Calabrese EJ, Baldwin LA (2001) Hormesis: a generalizable and unifying hypothesis. Crit Rev Toxicol 31:353-424

Calhoun VD, Altschul D, McGinty V, Shih R, Scott D, Sears E, Pearlson GD (2004) Alcohol intoxication effects on visual perception: an fMRI study. Hum Brain Mapp 21:15-26

Chan CY, Sun HS, Shah SM, Agovic MS, Friedman E, Banerjee SP (2014) Modes of direct modulation by taurine of the glutamate NMDA receptor in rat cortex. Eur J Pharmacol 728:167-175

Cooper ML, Frone MR, Russell M, Mudar P (1995) Drinking to regulate positive and negative emotions: a motivational model of alcohol use. J Pers Soc Psychol 69:990-1005
De Luca A, Pierno S, Camerino DC (2015) Taurine: the appeal of a safe amino acid for skeletal muscle disorders. J Transl Med 13:243

Deehan GA Jr, Knight CP, Waeiss RA, Engleman EA, Toalston JE, McBride WJ, Hauser SR, Rodd ZA (2016) Peripheral administration of ethanol results in a correlated increase in dopamine and serotonin within the posterior ventral tegmental area. Alcohol Alcohol 51:535-540

Degenhardt L, Chiu WT, Sampson N, Kessler RC, Anthony JC, Angermeyer M, Bruffaerts R, de Girolamo G, Gureje O, Huang Y, Karam A, Kostyuchenko S, Lepine JP, Mora ME, Neumark Y, Ormel JH, Pinto-Meza A, Posada-Villa J, Stein DJ, Takeshima T, Wells JE (2008) Toward a global view of alcohol, tobacco, cannabis, and cocaine use: findings from the WHO World Mental Health Surveys. PLoS Med 5:e141

Dzirkale Z, Pupure J, Rumaks J, Svirskis S, Vanina M, Mezhapuke R, Sile V, Fernandes MA, Duburs G, Klusa V (2011) Comparative study of taurine and tauropyrone: GABA receptor binding, mitochondrial processes and behaviour. J Pharm Pharmacol 63:230-237

Egan RJ, Bergner CL, Hart PC, Cachat JM, Canavello PR, Elegante MF, Elkhayat SI, Bartels BK, Tien AK, Tien DH, Mohnot S, Beeson E, Glasgow E, Amri H, Zukowska Z, Kalueff AV (2009) Understanding behavioral and physiological phenotypes of stress and anxiety in zebrafish. Behav Brain Res 205:38-44

Ferreira SE, de Mello MT, Rossi MV, Souza-Formigoni ML (2004a) Does an energy drink modify the effects of alcohol in a maximal effort test? Alcohol Clin Exp Research 28:1408-1412

Ferreira SE, Hartmann Quadros IM, Trindade AA, Takahashi S, Koyama RG, Souza-Formigoni ML (2004b) Can energy drinks reduce the depressor effect of ethanol? An experimental study in mice. Physiol Behav 82:841-847

Fillmore MT, Blackburn JS, Harrison EL (2008) Acute disinhibiting effects of alcohol as a factor in risky driving behavior. Drug Alcohol Depend 95:97-106

Fontana BD, Meinerz DL, Rosa LV, Mezzomo NJ, Silveira A, Giuliani GS, Quadros VA, Filho GL, Blaser RE, Rosemberg DB (2016) Modulatory action of taurine on ethanol-induced aggressive behavior in zebrafish. Pharmacol Biochem Behav 141:18-27

Fontana BD, Stefanello FV, Mezzomo NJ, Muller TE, Quadros VA, Parker MO, Rico EP, Rosemberg DB (2018) Taurine modulates acute ethanol-induced social behavioral deficits and fear responses in adult zebrafish. J Psychiatr Res 104:176-182

Foos TM, Wu JY (2002) The role of taurine in the central nervous system and the modulation of intracellular calcium homeostasis. Neurochem Res 27:21-26

Frosini M, Ricci L, Saponara S, Palmi M, Valoti M, Sgaragli G (2006) GABA-mediated effects of some taurine derivatives injected i.c.v. on rabbit rectal temperature and gross motor behavior. Amino Acids 30:233-242

Frye GD, Fincher A (1996) Sensitivity of postsynaptic GABAB receptors on hippocampal CA1 and CA3 pyramidal neurons to ethanol. Brain Res 735:239-248

Gebauer DL, Pagnussat N, Piato AL, Schaefer IC, Bonan CD, Lara DR (2011) Effects of anxiolytics in zebrafish: similarities and differences between benzodiazepines, buspirone and ethanol. Pharmacol Biochem Behav 99:480-486

Gerlai R, Lahav M, Guo S, Rosenthal A (2000) Drinks like a fish: zebra fish (Danio rerio) as a behavior genetic model to study alcohol effects. Pharmacol Biochem Behav 67:773-782

Goodman FR, Stiksma MC, Kashdan TB (2018) Social Anxiety and the Quality of Everyday Social Interactions: The Moderating Influence of Alcohol Consumption. Behav Ther 49:373-387

Grant BF, Dawson DA, Stinson FS, Chou SP, Dufour MC, Pickering RP (2004) The 12-month prevalence and trends in DSM-IV alcohol abuse and dependence: United States, 1991-1992 and 2001-2002. Drug Alcohol Depend 74:223-234 
Huxtable RJ (1992) Physiological actions of taurine. Physiol Rev 72: $101-163$

Johansson AK, Hansen S (2000) Increased alcohol intake and behavioral disinhibition in rats with ventral striatal neuron loss. Physiol Behav 70:453-463

Kalueff AV, Gebhardt M, Stewart AM, Cachat JM, Brimmer M, Chawla JS, Craddock C, Kyzar EJ, Roth A, Landsman S, Gaikwad S, Robinson K, Baatrup E, Tierney K, Shamchuk A, Norton W, Miller N, Nicolson T, Braubach O, Gilman CP, Pittman J, Rosemberg DB, Gerlai R, Echevarria D, Lamb E, Neuhauss SC, Weng W, Bally-Cuif L, Schneider H, Zebrafish Neuroscience Research C (2013) Towards a comprehensive catalog of zebrafish behavior 1.0 and beyond. Zebrafish 10:70-86

Krystal JH, Petrakis IL, Krupitsky E, Schutz C, Trevisan L, D'Souza DC (2003) NMDA receptor antagonism and the ethanol intoxication signal: from alcoholism risk to pharmacotherapy. Ann N Y Acad Sci 1003:176-184

Kushner MG, Sher KJ, Beitman BD (1990) The relation between alcohol problems and the anxiety disorders. Am J Psychiatry 147:685-695

Lambert IH, Kristensen DM, Holm JB, Mortensen OH (2015) Physiological role of taurine-from organism to organelle. Acta Physiol (Oxf) 213:191-212

Lasek AW (2016) Effects of ethanol on brain extracellular matrix: implications for alcohol use disorder. Alcohol Clin Exp Res 40:20302042

Lerdweeraphon W, Wyss JM, Boonmars T, Roysommuti S (2013) Perinatal taurine exposure affects adult oxidative stress. Am J Physiol Regul Integr Comp Physiol 305:R95-R97

Levin ED, Bencan Z, Cerutti DT (2007) Anxiolytic effects of nicotine in zebrafish. Physiol Behav 90:54-58

Lydiard RB (2003) The role of GABA in anxiety disorders. J Clin Psychiatry 64(Suppl 3):21-27

Marczinski CA, Fillmore MT (2014) Energy drinks mixed with alcohol: what are the risks? Nutr Rev 72(Suppl 1):98-107

Maximino C, de Brito TM, Colmanetti R, Pontes AA, de Castro HM, de Lacerda RI, Morato S, Gouveia A Jr (2010a) Parametric analyses of anxiety in zebrafish scototaxis. Behav Brain Res 210:1-7

Maximino C, de Brito TM, da Silva Batista AW, Herculano AM, Morato S, Gouveia A Jr (2010b) Measuring anxiety in zebrafish: a critical review. Behav Brain Res 214:157-171

Mezzomo NJ, Fontana BD, Kalueff AV, Barcellos LJG, Rosemberg DB (2018) Understanding taurine CNS activity using alternative zebrafish models. Neurosci Biobehav Rev 90:471-485

Mezzomo NJ, Silveira A, Giuliani GS, Quadros VA, Rosemberg DB (2016) The role of taurine on anxiety-like behaviors in zebrafish: A comparative study using the novel tank and the light-dark tasks. Neurosci Lett 613:19-24

Montesinos J, Alfonso-Loeches S, Guerri C (2016) Impact of the innate immune response in the actions of ethanol on the central nervous system. Alcohol Clin Exp Res 40:2260-2270

Nutt DJ, Peters TJ (1994) Alcohol: the drug. Br Med Bull 50:5-17

Oliveira TA, Koakoski G, Kreutz LC, Ferreira D, da Rosa JG, de Abreu MS, Giacomini AC, Oliveira RP, Fagundes M, Piato AL, Barreto RE, Barcellos LJ (2013) Alcohol impairs predation risk response and communication in zebrafish. PloS one 8:e75780

Olsen RW, Liang J (2017) Role of GABAA receptors in alcohol use disorders suggested by chronic intermittent ethanol (CIE) rodent model. Mol Brain 10:45
Parker MO, Millington ME, Combe FJ, Brennan CH (2012) Housing conditions differentially affect physiological and behavioural stress responses of zebrafish, as well as the response to anxiolytics. PloS one 7:e34992

Patrick ME, Evans-Polce RJ, Maggs JL (2014) Use of alcohol mixed with energy drinks as a predictor of alcohol-related consequences two years later. J Stud Alcohol Drugs 75:753-757

Rosemberg DB, Braga MM, Rico EP, Loss CM, Cordova SD, Mussulini BH, Blaser RE, Leite CE, Campos MM, Dias RD, Calcagnotto ME, de Oliveira DL, Souza DO (2012) Behavioral effects of taurine pretreatment in zebrafish acutely exposed to ethanol. Neuropharmacology 63:613-623

Rosemberg DB, Rico EP, Mussulini BH, Piato AL, Calcagnotto ME, Bonan CD, Dias RD, Blaser RE, Souza DO, de Oliveira DL (2011) Differences in spatio-temporal behavior of zebrafish in the open tank paradigm after a short-period confinement into dark and bright environments. PloS one 6:e19397

Schaffer SW, Jong CJ, Ramila KC, Azuma J (2010) Physiological roles of taurine in heart and muscle. J Biomed Sci 17(Suppl 1):S2

Schroder KE, Perrine MW (2007) Covariations of emotional states and alcohol consumption: evidence from 2 years of daily data collection. Soc Sci Med 65:2588-2602

Snipes DJ, Benotsch EG (2013) High-risk cocktails and high-risk sex: examining the relation between alcohol mixed with energy drink consumption, sexual behavior, and drug use in college students. Addict Behav 38:1418-1423

Stewart AM, Ullmann JF, Norton WH, Parker MO, Brennan CH, Gerlai R, Kalueff AV (2015) Molecular psychiatry of zebrafish. Mol Psychiatry 20:2-17

Tasan RO, Bukovac A, Peterschmitt YN, Sartori SB, Landgraf R, Singewald N, Sperk G (2011) Altered GABA transmission in a mouse model of increased trait anxiety. Neuroscience 183:71-80

Tran S, Gerlai R (2013) Time-course of behavioural changes induced by ethanol in zebrafish (Danio rerio). Behav Brain Res 252:204-213

Turner S, Mota N, Bolton J, Sareen J (2018) Self-medication with alcohol or drugs for mood and anxiety disorders: A narrative review of the epidemiological literature. Depress Anxiety 35:851-860

Vitvitsky V, Garg SK, Banerjee R (2011) Taurine biosynthesis by neurons and astrocytes. J Biol Chem 286:32002-32010

Wallner M, Olsen RW (2008) Physiology and pharmacology of alcohol: the imidazobenzodiazepine alcohol antagonist site on subtypes of GABAA receptors as an opportunity for drug development? Br J Pharmacol 154:288-298

Wong K, Elegante M, Bartels B, Elkhayat S, Tien D, Roy S, Goodspeed J, Suciu C, Tan J, Grimes C, Chung A, Rosenberg M, Gaikwad S, Denmark A, Jackson A, Kadri F, Chung KM, Stewart A, Gilder T, Beeson E, Zapolsky I, Wu N, Cachat J, Kalueff AV (2010) Analyzing habituation responses to novelty in zebrafish (Danio rerio). Behav Brain Res 208:450-457

Wu JY, Prentice H (2010) Role of taurine in the central nervous system. J Biomed Sci 17(Suppl 1):S1

Publisher's note Springer Nature remains neutral with regard to jurisdictional claims in published maps and institutional affiliations. 